\title{
Assessment of Exclusive Breastfeeding and Associated Factors among ANC and Non-ANC Mothers in Ethiopian Great Rift Valley, 2016
}

\section{Bacha Kitesa*}

Department of Public health, College of Health science, Arsi University and Program officer at World Vision, Asella, Ethiopia

*Corresponding author: Bacha Kitesa B.Sc, MPH, Department of Public health,

Research Article

Volume 1 Issue 3

Received Date: October 12, 2017

Published Date: October 23, 2017

College of Health science, Arsi University and Program officer at World Vision, Asella, Ethiopia, Tel: +251934095831; Email: bachakitesa@gmail.com

\section{Abstract}

Introduction: Exclusive breastfeeding is an important public health strategy for improving child and maternal health conditions. However, the practice of exclusive breastfeeding is very low in many developing countries including Ethiopia though the level remains unknown in study district.

Objective: To assess magnitude of exclusive breastfeeding and associated factors among infants in Marti Arsi Zone, Oromia Region, Ethiopia.

Methods: A community-based comparative cross sectional study design was conducted in Marti district, Arsi zone, Oromiya Region, Ethiopia from March 17- 30/2016. A total of 2,222 mothers (i.e. 1,111 from mothers who attended and 1,111 from mothers who didn't attend antenatal care) were randomly selected from the district using multistage random sampling. Descriptive statistic was used to describe the variables and binary logistic regression model with adjusted odds ratio with 95\% confidence intervals was used to identify factors associated with exclusive breast feeding (EBF).

Results: Overall, 44.3\% (95\%CI: 42.2\%, 46.4\%) reported that they fed their infants exclusively. Of these, 567 (51\%) (95\%CI: 48.1\%, 54.0\%) and 417 (37.5\%) (95\% CI: 34.7\%, 40.5\%) mothers who attended antenatal care and did not were reported EBF, respectively. In bi- variable binary logistic regression analysis Age of mothers, religion of mothers, children attacked by diarrhea and place of delivery were found to be significantly associated with EBF among mothers that attended antenatal care while age of mothers, birth order of children, children attacked by diarrhea and frequency of breastfed were found to be significantly associated with exclusive breast feeding among those who didn't attend antenatal care. 
Conclusion: Exclusive breastfeeding was significantly lower among mothers that did not attend antenatal care than those who did. Thus, emphasis should be given to provide continuous exclusive breastfeeding education and counseling to mothers who did not visit the health facility for antenatal care at community level

Keywords: Exclusive Breast Feeding; ANC Mother; Non-ANC Mothers with Infants; Merti District

\section{Introduction}

Breast milk is a natural, renewable food that serves as a complete source of infant nutrition for the first six months of life. It has the appropriate balance of nutrients provided in a bio-available and easily digestible form, protecting both mothers and children against illnesses and diseases with unparalleled immunological and antiinflammatory properties [1]. Exclusive breastfeeding is defined as feeding an infant with only breast milk and no additional food, water, or other liquids (with the exception of medicines and vitamins, if needed) during the first six months of life [2]. Infants who are exclusively breastfed have less chance of becoming ill or dying from diarrhea and other infections. Exclusive breastfeeding is the most widely known and effective intervention for preventing early-childhood deaths. Optimum Exclusive breastfeeding practices can prevent 1.4 million deaths worldwide among children under five every year [3]. Suboptimal breastfeeding contributes to $45 \%$ of neonatal infectious deaths, $30 \%$ of diarrheal deaths and $18 \%$ of acute respiratory deaths among children under five in developing countries [4]. It is also responsible for $10 \%$ of the disease burden in children younger than 5 years old [5]. EBF is associated with multiple advantages to both, the baby and the mother. On the baby's side, there is acquisition of passive immunity against infection, nutrients for physical and mental development, emotional security and closeness to the mother. Being a dynamic and physiologically sensitive process, breast milk production is adjusted to suit the infant's requirement according to environmental changes. World Health Organization (WHO) and United Nations Children's Fund (UNICEF) recommend that all mothers should breastfeed their children exclusively for the first 6 months and there after they should continue to breastfeed for as long as the mother and child wish, and both appropriate and sufficient weaning food should be added after six months of life. Globally, fewer than 39\% of infants are exclusively breastfed during the first four months of life [6]. In developing countries, just $37 \%$ of infants less than 6 months old are exclusively breastfed. In Africa, less than one third of infants under 6 months old are exclusively breastfed [7]. In Ethiopia approximately half (52\%) of children less than six months old are exclusively breastfed. The practice of EBF at age $0-1$ month is $70 \%, 55 \%$ at $2-3$ months and 32\% among 4-5 month old infants [8]. The Health Sector Development Program (HSDP) IV has set a target to increase exclusive breastfeeding from $49 \%$ to $70 \%$ in Ethiopia by the end of 2015 [9].

In order to achieve the Sustainable Development Goal (SDG) of reduction of child mortality, infant breastfeeding has been identified as one of the major intervention areas both globally and nationally. Based on several studies done in Ethiopia, breastfeeding is nearly universal but the proportion of exclusively breastfed children up to 6 months is less than the optimal recommendations (For the first six months of life, infants should be exclusively breast fed to achieve optimal growth, development and health. Thereafter, infants should receive nutritionally adequate and safe complementary foods, while continuing to breast feed for up to two years or more).

There is compelling scientific evidence that exclusive breastfeeding of infants could prevent around a million deaths of children under-five age in the developing world. Yet global rates of exclusive breastfeeding rates have remained stagnant since 1990 with only 36 per cent of children less than six months exclusively breastfed in 2012 [10]. In developing countries, of approximately 56 million infants less than six months of age, approximately 22 million are exclusively breastfed, while over 34 million children are not. Eighty per cent of these children who do not benefit from exclusive breastfeeding in developing countries live only in 29 countries. From these 29 countries, the 10 large countries including Ethiopia have two-thirds (over 21 million) of the approximate numbers of nonexclusively breastfed children in developing countries [11]. Pre-lacteal feeding, bottle feeding, discarding of the colostrums, and other cultural taboos play a significant role in poor caring and feeding practices. Children who are not exclusively breastfed have lower life expectancy are more vulnerable to disease, have decreased cognitive development, are less productive, and typically perform poorly in school. On top of that seasonal variances in food 
consumption, water availability, and sanitation practices are poorly understood but contribute greatly to the prevalence of malnutrition in Ethiopia. Investigation of the prevalence and determinant factors of the EBF may provide insight into the current burden and nature of the problem and help on how to direct prevention strategies. According to the EDHS-2011, Infant formula use at any age is uncommon in Ethiopia. Among the youngest breastfeeding children (0-1 month), 6 percent consume other milk and 3 percent consume other liquids. Consumption of other milk increases gradually with age until age 6-8 months, when 24 percent of breastfeeding children consume milk. Overall, almost four of every five breastfeeding children age 6-23 months (78 percent) consumed some solid or semi-solid food during the day or night preceding the survey. A comparison of dietary intake of children under two years of age by breastfeeding status shows that a higher proportion of non-breastfeeding children are consuming solid and semi-solid foods (84 percent) than breastfeeding children (57 percent).

This study would show the prevalence of EBF practice among mothers those attended antenatal care and not attended Antenatal care measure the association of demographic and service related factors, at investigating the period of breastfeeding and the factors with a possible impact on breastfeeding patterns in the women of the study area.

The magnitude and determinant factors for the practice of EBF in the study area is not known though assumed to be e primary task f HEWs. Hence, there is a need to carry out a research to come up with the magnitude and determinants of exclusive breastfeeding practice in the study area.

Health extension workers who are working at community level, Nurses and midwifes who work in maternity centers and in the community setting as well all other concerned bodies would utilize the result of this research as a reference in their counseling/health education session to minimize the sub-optimal exclusive breast feeding practice for the first six months of life.

\section{Objectives / General Objective}

To compare the magnitude of exclusive breast feeding and associated factors among ANC and on-ANC mothers with infants in Marti District, Arsi Zone, and Oromia Region, Ethiopia.

\section{Specific Objectives}

1. To compare the prevalence of exclusive breast feeding practice among ANC and no-ANC attendees mothers with infants

2. To identify factors associated with exclusive breast feeding practice among mothers with babies less than or twelve months who are on antenatal care and not.

\section{Methods}

\section{Study Area}

The study was conducted in Marti District, one of the 245 districts in Oromia region, found in Arsi zone, Ethiopia. The district is located at $205 \mathrm{~km}$ to the East of Addis Ababa, the capital city of Ethiopia and $160 \mathrm{~km}$ far away from Asella town, the capital of Arsi zone. The geographical location of Marti district is about $8^{0} 30^{\prime} \mathrm{N}$ Latitude and $30^{\circ} 50^{\prime} \mathrm{E}$ Longitude and it has an average elevation of 1800 meters above sea level.

Marti district had twenty three Keble's, of which four are urban and the remaining are rural. The study was conducted in Marti District, one of the 245 districts in Oromia region, found in Arsi zone, Ethiopia. The district is located at $205 \mathrm{~km}$ to the East of Addis Ababa, the capital city of Ethiopia and $160 \mathrm{~km}$ far away from Asella town, the capital of Arsi zone. The geographical location of Marti district is about $8^{\circ} 30^{\prime} \mathrm{N}$ Latitude and $30^{\circ} 50^{\prime}$ E Longitude and it has an average elevation of 1800 meters above sea level.

Merti district had twenty three kebeles, of which four are urban and the remaining rural. The district had one hospital, four health center, nineteen health post, one private clinic, fifty-five health professional and thirty nine health extension workers. Based on the projection of the 2007 population census, the district had an estimated 109,990 (56,863 males and 53,127 females) inhabitants. 2,777 mothers were attend ANC and from this 2,329 mothers are with infant those on ANC and there was no currently data about number of mothers with babies less than one year who were not on ANC in the district.

\section{Study Design and Period}

A community-based Comparative cross sectional study conducted from November 2015 to June 2016. 


\section{Source and Study Population}

Source population: Mothers of children less than or equal to 12 months living in Marti district attending antenatal care and not.

Study population: Mothers of children less than or equal to 12 months of age in the selected Keble's of Marti district attending antenatal care and not.

Inclusion criteria: Mothers with children age between six and twelve months inclusive in the selected Keble's of the District.

Exclusion criteria: Mothers whose children are too sick, have birth defect and Mothers who have any medical pathology which hinders breast-feeding.

\section{Sample Size and Sampling Procedures}

Sample size determination: The sample size for this study was determined by double population proportion formula assuming $52 \%$ prevalence of exclusive breastfeeding among mothers on ANC $\left(\mathrm{P}_{1}\right)$ and $41 \%$ prevalence of exclusive breastfeeding among mothers not on ANC $\left(\mathrm{P}_{2}\right), 80 \%$ power of the study, 95\% confidence level, one to one ratio and a design effect of two.

The final sample size resulted.

$$
\mathbf{n}=\left[\frac{\mathrm{z} \alpha \sqrt{2 \mathrm{p} 3 \mathrm{q} 3}+\mathrm{z} \beta \sqrt{(\mathrm{p} 1 \mathrm{q} 1+\mathrm{p} 2 \mathrm{q} 2}}{(\mathrm{p} 1-\mathrm{p} 2)}\right] 2
$$

$\mathrm{n}=$ on attend ANC and not on ANC ( $\mathrm{n} * 2)$

The calculated sample size using the above formula became $529 * 2=1058$. Considering $5 \%$ non-response rate, and multiply design effect of two, the final sample size considered was 2,222 .

\section{Sampling Procedure}

Sampling methods and procedure: Marti district had 23 Keble's (4 urban and 19 rural Keble's). Multistage sampling method was used by identifying 8 Keble's from the 23 Keble's of the Woredas using random selection and selecting the households by systematic random sampling. $(\mathrm{k}=8)$. The $1^{\text {st }}$ household was randomly selected from $1^{\text {st }} \mathrm{k}$ households by after geographically leveling the households in the Keble's with the local leaders. Finally one individual who was member of the family and mothers of children less than or equal to 12 months of age was randomly taken and interviewed.

Then, sample from eight (8) Keble's was determined using probability proportion to size (PAS) and total

Bacha Kitesa. Assessment of Exclusive Breastfeeding and Associated Factors among ANC and Non-ANC Mothers in Ethiopian Great Rift Valley, 2016. J Human Anat 2017, 1(3): 000113. household in these eight (8) Keble's was 4,000 that found in Abomsa 01kebele (558), Abomsa 02 (630), Homba (486), Dambaka Iftu (378), Dambaka Garjale (558), Hashe Ejersa (400), Shamo Gado(396) and Gado Arba (594) .

$\mathrm{nk}=\mathrm{n} \times \mathrm{Nk} / \mathrm{N}$

Where; nk =required sample size from each Keble $\mathrm{n}=$ the total Household from each Keble's

$\mathrm{NK}=$ total number of Household in each Keble $\mathrm{N}=$ total number of Household in Eight (8) Keble's $=4,000$ After that the sample size was allocated to each Keble as follows

\section{Variables of the Study}

Dependent Variable

Exclusive breastfeeding

\section{Independent Variables}

1. Socio-Demographic factors

Economic,

Environment

Employment,

Maternal age

Religious

Maternal related

Ethnicity

Marital status

Educational status

2. Psychosocial factors

Cultural,

Parity

Health care providers

Health knowledge and belief

3. EBF experiences:

Duration

Delivery place

Vaccination

Antenatal care Breast feeding counseling during pregnancy

Mother's knowledge on breastfeeding

Mother's perception on breast milk adequacy

\section{Operational Definition}

Breast-feeding: The child has received breast milk at least for six month.

$>$ Exclusive breast-feeding: Breast feeding while giving no other foods or drinks even water with the exception of drops or syrups of medicine at least for six month.

$>$ Infant feeding practice: Infant breast feeding that is usually or regularly done often as a habit, tradition or custom. 
Replacement feeding: The process of feeding a child who is not receiving any breast milk with a diet that provides all the nutrients the child needs.

$>$ Infant feeding practice perception: Awareness/the ability to understand and make good judgments about infant feeding

$>$ Exposed: Mothers who are not attending ANC and postnatal care having children less or equal to twelve months

$>$ Unexposed: Mothers attended either ANC or PNC having children less than or equal to twelve month

\section{Data Collection Procedures (Instruments, Personnel, Measurements)}

Data was collected using structured and pretested questionnaire through interview. The questionnaires was developed and organized after literature review. It was prepared in English and then translated to Afan- Oromo and back to English to check for its consistency. The questions included about socio-demographic, economic status, maternal, and infant health service influencing factors. The questionnaires was pre-tested before the data collection procedure begins that was not included in the actual main survey having with similar study subjects. Data collectors nurses were those graduated in diploma level and employed as health extension workers. All data collectors were females in order to minimize the communication problems with the study subjects. One supervisor was selected from the BSC Nurses who had better exposure for supervision on the area of research data collection. Basically data quality was assured by training data collectors and supervisor. The training was given appropriately for two days.

After giving training, close follow up was done by supervisor and same time questionnaire was checked for its completeness. Discussion was made with the data collectors and supervisors at the end of the day and in the morning to minimize the errors create during the interview and to take corrective actions alarmingly.

\section{Data Quality Assurance}

Data was assured through questionnaire preparation, pre-testing of the questionnaire for its understandability by $5 \%$ of sample on volunteer individuals in Keble's which was not included in the actual, closely following the day-to-day data collection process to ensure completeness and consistency of questionnaire and non over lapping numerical code was given for each questions and the coded data was then entered into SPSS software Version 20.

\section{Data Processing and Analysis}

Data was entered into Statistical Package for the Social Sciences (SPSS) software version 20 for father analysis. Descriptive statistics was done for all the variable. To identify factor associated with exclusive breast feeding binary logistic regression With Odds ratio and 95\% confidence interval was done. P-value less than 0.05 was used to ascertain the association of each independent variables.

\section{Ethical Consideration}

After I had taken ethical clearance letter from ARU, College of health science and official letter was written from Arsi zone department of health then submitted this formal supporting letter to Marti district health offices to do the research. The study subjects were informed that they had the right to withdraw from the study at any time. The explanation was based on omitting name of the study participants from the questionnaire, by telling the safety of the place where the questionnaire would be stored after data collection and also the analysis was not for individual it is for groups. The subject was assured of confidentiality of results and purpose of study risks and benefits of the study was explained. They were also telling about use of the codebook and assigning numbers other than names to promote anonymity. Time frame for the questionnaire was given as 20 minutes for each participant. A subject was allowed to asked questions and after they agreed to become subjects they sign the consent form.

\section{Results}

\section{Descriptive Results}

Socio-demographic characteristics of mothers: A total of 2,222 Mothers were included in the study and 100\% response was obtained from the respondents. From the respondents $1,888(85 \%)$ of mothers were married, while 955(86\%) mothers were attended ANC and $933(83 \%)$ were not. Majority of mothers were Oromo $1633(73.5 \%)$ from these $778(70 \%)$ were attended ANC and $855(77 \%)$ not. mothers age between $25-29$ years were $728(33 \%)$ from these $372(34.5 \%)$ attended ANC and 356 (32\%) not. Majority of mothers $1272(57 \%)$ were Muslims, from these $611(55 \%)$ were attended ANC and 661 (59.5\%) not. The mean $( \pm$ SD) age of mothers was 26.7 ( \pm 5.8$)$ years. 
About 906 (40.8\%) of mothers were illiterate or have no formal education from these $350(31 \%)$ were attended ANC and $556(50 \%)$ not. Majority of respondents were house wife that is about $1572(70.7 \%)$ from these 833(75\%) attended ANC and 739(66.5) not. only $178(8 \%)$ mothers were government employees, from these 61(5.5\%) mothers were attended ANC and 117 (10.5\%) not. Majority of mothers 1850 (83.2\%) family income per month in birr were 100-500 birr in the study area from these mothers those attended ANC were 911(82\%) and not attended ANC were 939 (84.5\%) (Table 1).

\begin{tabular}{|c|c|c|c|}
\hline \multicolumn{2}{|c|}{ Category $(\mathrm{N}=2,222)$} & $\mathbf{N}$ & Percentage \\
\hline \multirow{2}{*}{ Residences of mother } & Urban & 676 & $30.40 \%$ \\
\hline & Rural & 1546 & $69.60 \%$ \\
\hline \multirow{4}{*}{ Marital status of mother } & Single & 124 & $5.60 \%$ \\
\hline & Living together & 1888 & $85.00 \%$ \\
\hline & Widow & 121 & $5.40 \%$ \\
\hline & Divorced & 89 & $4.00 \%$ \\
\hline \multirow{3}{*}{ Age of mother (in years) } & $6-8$ & 955 & $43 \%$ \\
\hline & $9-10$ & 734 & $33 \%$ \\
\hline & $11-12$ & 533 & $24 \%$ \\
\hline \multirow{4}{*}{ Ethnicity } & Oromo & 1746 & $78.60 \%$ \\
\hline & Amhara & 436 & $19.60 \%$ \\
\hline & Tiger & 23 & $1.00 \%$ \\
\hline & Garage & 17 & $0.80 \%$ \\
\hline \multirow{4}{*}{ Educational back ground } & None & 906 & $40.80 \%$ \\
\hline & Primary school & 999 & $45.00 \%$ \\
\hline & Secondary school & 289 & $13.00 \%$ \\
\hline & College and above & 28 & $1.30 \%$ \\
\hline \multirow{4}{*}{ Religion } & Orthodox & 777 & $35.00 \%$ \\
\hline & Protestant & 151 & $6.80 \%$ \\
\hline & Muslim & 1272 & $57.20 \%$ \\
\hline & Catholic & 22 & $1.00 \%$ \\
\hline \multirow{6}{*}{ Occupation } & House wife & 1575 & $70.90 \%$ \\
\hline & Merchant & 178 & $8.00 \%$ \\
\hline & Governmental or NGO Employee & 175 & $7.90 \%$ \\
\hline & Student & 184 & $8.30 \%$ \\
\hline & Farmer & 99 & $4.50 \%$ \\
\hline & House servant & 11 & $0.50 \%$ \\
\hline \multirow{5}{*}{$\begin{array}{l}\text { Family income per month } \\
\text { in birr }\end{array}$} & $100-500$ & 1850 & $83.20 \%$ \\
\hline & $600-1000$ & 256 & $11.50 \%$ \\
\hline & $1100-1500$ & 39 & $1.80 \%$ \\
\hline & $1600-2000$ & 44 & $2 \%$ \\
\hline & $>2000$ & 33 & $1.50 \%$ \\
\hline
\end{tabular}

Table 1: Socio-demographic characteristics of mothers with infants aged less than Twelve month in Merti District Arsi Zone Oromia region.

Psychosocial Factors on Practice of the Infant Feeding Situation: Majority of respondents mothers $1755(79 \%)$ had given colostrum to their child, 999(45\%) respondents mothers had visited health facilities when their child begin teethes, 956(43\%) of mothers continue breastfeeding when their child begins teething, 555(25\%) of mothers forces to stop breast feeding due to access of bottle feeding, 261(11.7\%) of mothers forces to stop breast feeding due to cultural conditions like available of Abish feeding, 111(5\%) of mothers seems as useless if infant get colostrum's, from these $50(4.5 \%)$ of them were those attend ANC and 61(5.5\%) were not. 244(11\%) of 
mothers because cultural situation their infant not get colostrum, from these $122(11 \%)$ of them were those attend ANC and 122(11\%) were not. $884(39.8 \%)$ of mothers were given to their babies anything to drink before Six month, from these $417(38 \%)$ of them were those attend ANC and 467(42\%) were not. $650(29 \%)$ of mothers were given fresh milk for drinking to their babies, from these $289(26 \%)$ of them were those attend ANC and 361(32.5\%) were not (Table 2).

\begin{tabular}{|c|c|c|c|}
\hline \multicolumn{2}{|l|}{ Category $(\mathrm{N}=2,222)$} & $\mathbf{N}$ & Percentage \\
\hline \multirow{2}{*}{$\begin{array}{l}\text { Child had diarrhea recurrently during the first six } \\
\text { months }\end{array}$} & Yes & 444 & $20.0 \%$ \\
\hline & No & 1778 & $80.0 \%$ \\
\hline \multirow{4}{*}{ when child begins teething, mothers ..... } & discontinue breast feeding & 188 & $8.5 \%$ \\
\hline & continue breast feeding & 958 & $43.1 \%$ \\
\hline & visit health facilities & 1002 & $45.1 \%$ \\
\hline & visit cultural leaders & 74 & $3.3 \%$ \\
\hline \multirow{5}{*}{ reason for not giving colostrums to your infant } & It seems useless & 111 & $5.0 \%$ \\
\hline & Because of cultural situation & 134 & $6.0 \%$ \\
\hline & Because of dirty & 56 & $2.5 \%$ \\
\hline & Others(didn't remember) & 56 & $2.5 \%$ \\
\hline & Infant get colostrums & 1865 & $83.9 \%$ \\
\hline
\end{tabular}

Table 2: Psychosocial factors on Practice of the infant feeding situation In Marti District Arsi Zone Oromia region.

Exclusive Breastfeeding (EBF) Practices of the Mothers: About 1257(56.6\%) of the respondents gave birth at home and $965(43.4 \%)$ at health institution. About 954(42.9\%) of the respondents delivered by the help of traditional birth attendants (TBA); 451(20.3\%) of mothers delivery assisted by nurse, 573(25.8\%) mothers delivery conducted by doctor and 244(11\%) mothers delivered at home by their family, only $925(41.6 \%)$ mothers were didn't heard about exclusive breast feeding and $944(41.5 \%)$ of the respondents mothers source of information about exclusive breastfeeding were health exestuations workers. About 1844(83\%) of the respondents mothers child have been vaccinated and $378(17 \%)$ were no vaccinated (Table 3$)$.

\begin{tabular}{|c|c|c|c|}
\hline \multicolumn{2}{|c|}{ Category (N=2,222) } & Frequency & Percentage \\
\hline \multirow{2}{*}{ Place of Child born } & At home & 1257 & $56.6 \%$ \\
\cline { 2 - 4 } & At health institutions & 965 & $43.4 \%$ \\
\hline \multirow{3}{*}{ Delivery was conducted by } & Nurses & 451 & $20.3 \%$ \\
\cline { 2 - 4 } & Doctors & 573 & $25.8 \%$ \\
\cline { 2 - 4 } & TBA & 954 & $42.9 \%$ \\
\cline { 2 - 4 } & Others(Her own family) & 244 & $11.0 \%$ \\
\hline \multirow{2}{*}{ Child have been vaccinated } & Yes & 1844 & $83.0 \%$ \\
\cline { 2 - 4 } & No & 378 & $17.0 \%$ \\
\hline
\end{tabular}

Table 3: Exclusive breastfeeding (EBF) experiences of mothers with infants aged less than twelve months in Merti District Arsi Zone Oromia region.

Media Access and Source of Information about Exclusive Breastfeeding: About 1355(61\%) of the respondents mothers heard about EBF and only $867(39 \%)$ were not, mothers were heard about exclusive breast feeding on the topic of benefits of breastfeeding were $603(27.1), 265(11.9)$ on the topic of exclusive breastfeeding and 925(41.6\%) mothers had not known about this message and 944(42.5\%) of the respondents mothers Source of information about exclusive breastfeeding were health extension workers (Table 4). 


\begin{tabular}{|c|c|c|c|}
\hline \multirow{2}{*}{ Category(N=2,222) } & Frequency & Percentage \\
\hline \multirow{3}{*}{ Have you heard about EBF } & Yes & 1355 & $61.00 \%$ \\
\cline { 2 - 4 } & No & 867 & $39.00 \%$ \\
\hline \multirow{4}{*}{\begin{tabular}{l} 
What were you told \\
\cline { 2 - 4 }
\end{tabular}} & Benefits of breast feeding & 603 & $27.10 \%$ \\
\cline { 2 - 4 } & Exclusive breast feeding & 265 & $11.90 \%$ \\
\cline { 2 - 4 } & How feed breast feeding & 274 & $12.30 \%$ \\
\hline \multirow{3}{*}{$\begin{array}{c}\text { Source of information about } \\
\text { exclusive breastfeeding }\end{array}$} & Contents of breast feeding & 155 & $7.00 \%$ \\
\cline { 2 - 4 } & I do not known & 925 & $41.60 \%$ \\
\cline { 2 - 4 } & Radio & 242 & $10.90 \%$ \\
\cline { 2 - 4 } & Television & 64 & $2.90 \%$ \\
\cline { 2 - 4 } & HEWs & 944 & $42.50 \%$ \\
\cline { 2 - 4 } & Other HWs & 34 & $1.50 \%$ \\
\cline { 2 - 4 } & VCHWs & 33 & $1.80 \%$ \\
\hline
\end{tabular}

Table 4: Media access and source of information about Exclusive Breastfeeding mothers with infants aged less than twelve months in Merti District Arsi Zone Oromia region.

Knowledge of mothers to ward exclusive breastfeeding in marti district: About 2023(91\%) of the respondents mothers had good knowledge on the first milk/colostrums be given to their infant and only $199(9 \%)$ had poor knowledge on the first milk/colostrum be given to their infant, $1633(73.5 \%)$ respondents mothers had a good knowledge on breast milk alone without water and other liquids enough for an infant during the first 6 months of life and 2195(98.8) respondents mothers were had a good knowledge on starting from 6 months, infant start complementary feeding and continued breastfeeding up to 2 years and beyond (Table 5).

\begin{tabular}{|c|c|c|c|}
\hline \multicolumn{2}{|l|}{ Category $(\mathrm{N}=2,222)$} & Frequency & Percentage \\
\hline \multirow{2}{*}{ Colostrums be given to an infant } & Yes & 2023 & $91.0 \%$ \\
\hline & No & 199 & $9.0 \%$ \\
\hline \multirow{2}{*}{$\begin{array}{l}\text { Is breast milk alone without water and other liquids enough for an } \\
\text { infant during the first } 6 \text { months of life? }\end{array}$} & Yes & 1633 & $73.5 \%$ \\
\hline & No & 589 & $26.5 \%$ \\
\hline \multirow{2}{*}{$\begin{array}{l}\text { Starting from } 6 \text { months, infant start complementary feeding and } \\
\text { continued breastfeeding up to } 2 \text { years and beyond }\end{array}$} & Yes & 2195 & $98.8 \%$ \\
\hline & No & 27 & $1.2 \%$ \\
\hline
\end{tabular}

Table 5: Breastfeeding knowledge of mothers with infants aged less than twelve months In Merti District Arsi Zone Oromia region.

Breastfeeding Perception of Mothers: About $2100(94.5 \%)$ of the respondents mothers had a good Perception on exclusive breastfeeding is important for child health, 1916(86.2\%) respondents mothers were had a good Perception on an infant be put to breast immediately after birth and about 2209(99.4\%) mothers had good Perception on prelate-feeding needed for an infant before starting breast milk (Table 6). 


\begin{tabular}{|c|c|c|c|}
\hline \multicolumn{2}{|c|}{ Category(N=2,222) } & & Frequ \\
ency & $\begin{array}{l}\text { Perce } \\
\text { ntage }\end{array}$ \\
\hline $\begin{array}{c}\text { Is exclusive breastfeeding } \\
\text { important for child health }\end{array}$ & yes & 2100 & $94.50 \%$ \\
\cline { 2 - 4 } $\begin{array}{c}\text { Should an infant be put to } \\
\text { breast immediately after birth }\end{array}$ & yes & 122 & $5.50 \%$ \\
\cline { 2 - 4 } $\begin{array}{l}\text { Is prelacteal feeding needed for } \\
\text { an infant before starting breast } \\
\text { milk }\end{array}$ & yes & 13 & $86.20 \%$ \\
\hline
\end{tabular}

Table 6: Breastfeeding Perception of mothers with infants aged less than twelve months In Merti District Arsi Zone Oromia region.

\section{Factors Associated with Exclusive Breastfeeding}

In bi-variable binary logistic regression analysis age of mothers, ethnicity, educational statues, religion of mothers, occupational statues, birth order of children, birth interval of children, child begins teething, children attacked by diarrhea, infant get colostrum, place of children had delivered, frequency of breast fed their children per day, currently breast fed their children, how long did you stay in the health institution after delivery, child have been vaccinated and perception of mothers were significantly associated with exclusive breastfeeding. However in multivariable binary logistic regression analysis among mothers who attended antenatal care only age of mothers, religion of mothers, children attacked by diarrhea, place of children had delivered were found to be associated factors with exclusive breastfeeding, while age of mothers, birth order of children, children attacked by diarrhea and frequency of breast fed their children per day among mothers those not followed antenatal care were found to be associated factors with exclusive breastfeeding.

Elder mothers among attended antenatal care were 1.23 times more likely to be exclusively breast feed than the younger mothers [AOR=1.23;95\% CI:1.18,1.27], while elder mothers among not attended antenatal care were 1.17 times more likely to be exclusively breast feed than the younger mothers[AOR=1.17;95\% CI:1.14,1.21].
In another hand among mothers who attended antenatal care their children had not attacked by diarrhea were 63.34 times more likely to be exclusively breast fed compared to children were attacked by diarrhea $[\mathrm{AOR}=$ 63.34; 95\% CI:31.7,126.4], while mothers among not attended antenatal care who their children were not attacked by diarrhea were 1.58 times more likely to be exclusively breast fed compared to children were attacked by diarrhea [AOR=1.58;95\% CI:1.08,2.30].

In the study area Muslim followers among mothers attended antenatal care were 0.10 times less likely to be exclusively breastfed than orthodox mothers [AOR= $0.10 ; 95 \%$ CI:0.07,0.15], while catholic and protestant followers mothers those attended antenatal care were 0.56 times less likely to be exclusively breastfed than orthodox mothers [AOR= 0.56;95\% CI:0.21,1.51].

Furthermore, the study found that mothers who delivered at health institution among mothers who attended antenatal care were 0.15 times less likely to be exclusively breastfed than mothers who delivered at home [AOR= $0.15 ; 95 \% \mathrm{CI}: 0.11,0.22]$.

Among mothers not attended antenatal care those born at two years interval were 2.14 times more likely to be exclusively breastfed than who born at one year's interval [AOR= 2.14;95\% CI:1.52,3.01], Among mothers not attended antenatal care those birth order at two children interval were 2.14 times more likely to be exclusively breastfed than who birth order at one children [AOR= $2.14 ; 95 \%$ CI:1.52,3.01], Mothers who birth order at three children interval from not attended antenatal care were 0.02 times less likely to be exclusively breastfed than those at one children [AOR= 0.02;95\% CI:0.01,0.04].

Mothers who birth order greater than three children interval not attended antenatal care were 1.78 times more likely to be exclusively breastfed than those born at one children interval $[\mathrm{AOR}=1.78 ; 95 \% \mathrm{CI}: 1.17,2.71]$.

Mothers who breast fed their children six and above times per day among mothers not attended antenatal care were 0.08 times less likely to be exclusively breastfed than gave breast feed to their children $>6$ time per day [AOR=0.08;95\% CI: 0.04,0.15]. (See table 7 below)

\begin{tabular}{|c|c|c|c|c|c|c|c|c|c|}
\hline \multirow{3}{*}{ Characters } & \multicolumn{4}{|c|}{ Exclusive breast feeding on } & \multicolumn{4}{c|}{ Exclusive breast feeding not on } \\
ANC(N=1,111) & \multicolumn{3}{c|}{ ANC(N=1,111) } & \multicolumn{1}{|c|}{} \\
\cline { 2 - 9 } & Yes & No & COR(95\%C.I) & AOR(95\% CI) & Yes & No & COR(95\%C.I) & A0R(95\% CI) & P-Value \\
\hline Age of mothers & 567 & 544 & $0.91[0.89,0.93]$ & $1.23[1.18,1.27]$ & 417 & 694 & $0.91[0.89,0.93]$ & $1.17[1.14,1.21]$ & 0.00 \\
\hline Religious & & & & & & & & & \\
\hline
\end{tabular}




\begin{tabular}{|c|c|c|c|c|c|c|c|c|c|c|}
\hline & Orthodox & 278 & 116 & 1 & & 239 & 144 & & & \\
\hline & Muslim & 336 & 275 & $6.41[4.68,8.78]$ & $0.102[0.068,0.15]$ & 415 & 246 & & --------- & 0.00 \\
\hline & Catholic\& protestant & 92 & 14 & $11.85[7.24,19.38$ & $0.56[0.21,1.51]$ & 40 & 27 & & --------- & 0.00 \\
\hline & ldren attacked by diarrh & & & & & & & & & \\
\hline & Yes & 13 & 204 & 1 & & 148 & 79 & 1 & & \\
\hline & No & 340 & 554 & $1.45[1.06,1.97]$ & $63.34[31.7,126.4]$ & 546 & 338 & $1.45[1.06,1.97]$ & $1.58[1.08,2.30]$ & 0.00 \\
\hline & Place of infant delivered & & & & & & & & & \\
\hline & At home & 340 & 132 & 1 & & 485 & 300 & & & \\
\hline & Health institutions & 227 & 412 & $9.94[7.35,13.46]$ & $0.15[0.11,0.22]$ & 209 & 117 & & 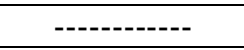 & 0.00 \\
\hline & irth order of the Childrel & & & & & & & & & \\
\hline & 1 & 189 & 181 & & & 116 & 231 & 1 & & \\
\hline & 2 & 155 & 150 & & ---------- & 185 & 136 & $1.07[0.79,1.45]$ & $2.14[1.52,3.01$ & 0.00 \\
\hline & 3 & 119 & 107 & & ----------- & 5 & 244 & $1.09[0.78,1.52]$ & $0.02[0.01,0.04]$ & 0.00 \\
\hline & $>3$ & 104 & 106 & & ------------ & 111 & 83 & $0.98[0.69,1.39]$ & $1.78[1.17,2.71]$ & 0.00 \\
\hline & quency to give breast / $\mathrm{c}$ & & & & & & & & & \\
\hline & Less than 6 times & 120 & 125 & & --.------- & 63 & 20 & 1 & & \\
\hline & 6 and above times & 424 & 442 & & -------- & 354 & 674 & $0.94[0.71,1.25]$ & $0.08[0.04,0.15]$ & 0.00 \\
\hline
\end{tabular}

Table 7: Factors associated with exclusive breastfeeding practices among mothers of one year age children attend antenatal care and not attend antenatal care in Merti District, Arsi Zone, Oromia Region, Ethiopia.

\section{Discussion}

This study disclosed that exclusive breastfeeding was significantly lower among mothers not following antenatal care than those who attended antenatal care. Age of mothers, religion of mothers, children attacked by diarrhea and place of deliver were found to be significantly associated with exclusive breastfeeding among mothers attended antenatal care while age of mothers, birth order of children, children attacked by diarrhea and frequency of breastfed were found to be significantly associated with exclusive breastfeeding among those who didn't attend ANC.

From the overall data reported out of the total mothers interviewed the prevalence of exclusive breast fed in Merti district were $44.3 \%$ they fed their infants exclusively while 567(51\%) and 417(37.5) mothers who attended antenatal care and did not are reported exclusive breast feeding respectively.

This result was lower than studies done in Jimma town (60.1\%), Goba district (71.3\%), Ghana (64\%), Nepal (66.6\%), Jordan (77\%), Madagascar, (70\%), Zambia, (74\%), Ghana, (79\%) and Bolivia (65\%). It is also less than the national findings for Amhara Region (81\%) and South Nations and Nationalities Peoples Region (64\%). But this finding is higher than the findings in Lebanon (10\%), Bangladesh (36\%) [12]. This difference is expected as our study area the study population were a lot cultural norm like bottle feeding is high and different value of living standards was contributed to the low prevalence of exclusive breastfeeding (EBF) . Also as infants grew older and older, the prevalence of exclusive breastfeeding decreases significantly indicating the overall lower duration of exclusive breastfeeding in the study community. This is common in many developing countries as majority of mothers believe that breast milk alone was not sufficient as the age of infants grew older. At this time mothers might have introduced complementary feeding for their infants due to the assumption that breast milk alone would not satisfy their needs as the infants are already older.

World Health Organization (WHO), global and national infant and young child feeding guidelines recommend that all newborns should be EBF for the first six months [13].

According to associated factors:- elder mothers among attended antenatal care were 1.23 times more likely to be exclusively breast feed than the younger mothers [AOR= $1.23 ; 95 \%$ CI:1.18,1.27], while elder mothers among non ANC attending were 1.17 times more likely to be exclusively breast feed than the younger mothers[AOR= $1.17 ; 95 \%$ CI:1.14,1.21]. This finding was in agreement with the study done in Deber brihan Amhara Regional State, of Ethiopia [14]. This could be due to the fact that 
younger age mothers do have a better job opportunity and lack the time to EBF their infant.

In the study area Muslim follower among mothers who attended antenatal care were 0.10 times less likely to exclusively breastfed than orthodox mothers [AOR= $0.10 ; 95 \%$ CI:0.07,0.15], in another hand catholic and protestant followers mothers attended antenatal care were 0.56 times less likely to be exclusively breastfed than orthodox mothers [AOR $=0.56 ; 95 \%$ CI:0.21,1.51]. Mothers among attended antenatal care those children attacked by diarrhea were 63.34 times more likely to be exclusively breastfed than mothers those their child not attacked [AOR=63.34; 95\%CI: 31.74, 126.39]. This result may be the culture of the believers' that using family planning is not recommend. If there is no long time interval between children birth the excretion of breast milk become low and the attachment of mother and child could be rough due to these reason exclusive breast feed also become low in the above mention characters.

Furthermore, the study found that mothers who delivered at health institution among mothers who attended antenatal care were 0.15 times less likely to exclusively breastfed than mothers who delivered at home [AOR= $0.15 ; 95 \% \mathrm{CI}: 0.11,0.22]$. Place of delivery has been found in a number of studies to be associated with exclusive breastfeeding. In the present study, delivery at a government health facility was no identified as a predictor of exclusive breastfeeding and this contradict to studies in Addis Ababa [15]. Delivery at hospital as a predictor can be attributed to the call made by WHO and UNICEF [16] for hospitals to be centers of breastfeeding. This initiative, undoubtedly, might have accounted for government health facility being a predictor of exclusive breastfeeding in the country. This study was in similar with study done in Nepal where by mothers who deliver at home are more likely to practice EBF. This is probably due to the fact that in Nepal according to study mothers who deliver are those that are rich and highly educated, where the situation is different in Marti context. In marti context may be the support from their husbands, friends, and neighbors influence the practice of exclusive breastfeeding.

Among mothers not attending antenatal care those born at two years interval were 2.14 times more likely to be exclusively breastfed than born at one year's interval [AOR $=2.14 ; 95 \% \mathrm{CI}: 1.52,3.01]$, in another hand those born at three years interval from not attended antenatal care were 0.02 times less likely to be exclusively breastfed than born at one year's interval [AOR $=0.02 ; 95 \%$ CI:0.01,0.04] and those born above three years interval not attended antenatal care were 1.78 times more likely to be exclusively breastfed than born at one year's interval $[\mathrm{AOR}=1.78 ; 95 \% \mathrm{CI}: 1.17,2.71]$.This means as the birth order of the children more gap the discharge of the breast milk become high and mothers can practices the exclusive breast feed.

Mothers among non ANC attendant children attacked by diarrhea were 1.58 times more likely to be exclusively breastfed than mothers those their child not attacked [AOR=1.58; 95\% CI: 1.08, 2.30]. This is due to the fact that lack of exclusive breast feed can cause diarrhea. The reason why mothers whose children affected by this diseases may be counseled by health profession on exclusive breast feeding during they visited health facility to find treatment for their children.

Frequency to breast feed children six and above times per day among mothers not attended antenatal care were 0.08 times less likely to be exclusively breastfed than gave breast feed to their children less than six time per day [AOR=0.08;95\% CI: $0.04,0.15]$. This is due to the fact that as the time of attachment of the children on the breast take long duration mothers become refuse to continue exclusive breast feed their children because of high friction between them.

\section{Limitations and Strengths}

\section{Strengths}

This study can be interpreted in light of its strengths and limitations. The use of validated questionnaires quantitative methods of data collection, $100 \%$ response was obtained from the respondents and comparative study design, The fact that this study did assess individual factors, including knowledge and attitude of mothers, as well as variables related to families, choosing and accommodating the study in Mart, seldom chosen place by researchers of any stream can be consider as a major strengths of this study.

\section{Limitations}

Other factors like health status of the mother and the child and other unmentioned factors which might be associated with exclusive breast feeding were not addressed in this study. In addition, not using enough literatures on this study area in specific due to the 
unavailability of published journals on the topic of interest could be mentioned as a limitation.

\section{Conclusion \& Recommendations}

\section{Conclusion}

A. The prevalence of exclusive breastfeeding practice was significantly lower among mothers who did not attended antenatal care than those who attended ANC in Marti district.

B. Age of mothers, birth order of children, children attacked by diarrhea and frequency had children get breastfed were significant factors of exclusive breastfeed among mothers who not attended antenatal care while age of mothers, religious of mother, children attacked by diarrhea and place of children had delivered were significant factors of exclusive breastfeed among mothers who attended antenatal care in Marti district.

\section{Recommendations}

Thus, emphasis should be given to provide continuous exclusive breastfeeding education and counseling to mothers who do not visit the health facility for antenatal care at community level.

Future breastfeeding promotion programmes by the government and partners should give special attention to those women who are not practicing EBF.

Younger age mothers do have a better job opportunity for the reason that they have no time to EBF their infant. Therefore improving awareness among youngest women toward exclusive breastfeeding through working environment.

\section{Acknowledgement}

First of all I thank my almighty God. Next I feel honored to acknowledge and express my sincere thanks to my advisors, supervisors, data collectors and study participants.

\section{References}

1. Foo LL, Quek SJ, Ng SA, Lim MT, Deurenberg-Yap M (2005) Breastfeeding prevalence and Practices among Singaporean Chinese. Malay and Indian mothers. Health Promot Int 20(3): 229-237.
2. Organization WHO (2003) Adherence to Long Term Therapies: Evidence for Action. Geneva.

3. WHO (1991) Indicaters for assessing breast feeding practies.

4. Motarjemi Y, Käferstein F, Moy G, Quevedo F (1993) Contaminated weaning food: a major risk Factor for diarrhea and associated malnutrition. Bull World Health Organ 71(1): 79-92.

5. Peters E, Wehkamp KH, Felberbaum RE, Krüger D, Linder $R$ (2006) Breastfeeding duration is Determined by only a few factors. Eur J Public Health 16(2): 162-167.

6. WHO (2009) Infant and young child feeding: model chapter for textbooks for medical students and allied health professionals.

7. Mullany LC, Li YM, Khatry SK, LeClerq SC, Darmstadt GL, et al. (2008) Breast-feeding Patterns, time to initiation, and mortality risk among newborns in southern Nepal. J Nutr 138(3): 599-603.

8. C. A. Exclusive breastfeeding - Does it make a difference?. Uppsala, Sweden: Uppsala University.

9. Mekuria G, Edris M (2015) Exclusive breastfeeding and associated factorsamong mothers in Debre Markos, NorthwestEthiopia: a cross-sectional study. Int Breastfeeding 10(1).

10. Yoon PW, Black RE, Moulton LH, Becker S (1996) Effect of Not Breastfeeding on the Risk of Diarrheal and Respiratory Mortality in Children under 2 Years of Age in Metro Cebu, the Philippines. Am J Epidemiol 143: $1142-1148$.

11. Labbok M, Krasovec K (1990) Toward consistency in breastfeeding definitions. Stud FAM Plann 21(4): 226230.

12. Setegn T, Belachew T, Gerbaba M, Deribe K, Deribew A, et al. (2012) Factors associated with exclusive breastfeeding practices among mothers in Goba district, south east Ethiopia: a cross-sectional study. Int Breastfeed J 7(1).

13. Agency CS. EDHS (2011) In: Agency CS, editor Addis Ababa, Ethiopia March 2012. 
14. Maeza MA, Mesele DA, Zelalem KK (2015) Factors associated with exclusive breastfeeding practices in Debre Berhan District, Central Ethiopia: a cross sectional community based study. Int Breastfeeding J 10(23).

15. Tesfa GW, Addisu WK, Melkie E (2014) Assessment of exclusive breast feeding practice and associated factors in Mecha district, North west Ethiopia2(4): 330-336.

16. Geneva WHO (1991) Indicaters for assessing breast feeding practies. 